\title{
Water Solubility in Linear Fluoroalkanes Used in Blood Substitute Formulations
}

\author{
Mara G. Freire, ${ }^{\ddagger}$ Lígia Gomes, ${ }^{\dagger}$ Luís M. N. B. F. Santos, ${ }^{\S}$ Isabel M. Marrucho, ${ }^{\ddagger}$ and \\ João A. P. Coutinho*, \\ CICECO, Departamento de Química, Universidade de Aveiro, Aveiro, Portugal, CBFC, Faculdade de Ciências \\ da Saúde, Universidade Fernando Pessoa, Porto, Portugal, and Centro de Investigação em Química, \\ Departamento de Química, Faculdade de Ciências, Universidade do Porto, Porto, Portugal
}

Received: April 13, 2006; In Final Form: August 18, 2006

\begin{abstract}
The interactions between water and $n$-perfluoroalkanes or substituted $\alpha-(\omega$-)fluoroalkanes used in blood substitute formulations were investigated experimentally and using ab initio calculations. The solubility of water in $\mathrm{C}_{6}-\mathrm{C}_{9}$ perfluoroalkanes and five $\mathrm{C}_{8}$ analogues of substituted fluoroalkanes was measured in the temperature range between 288 and $318 \mathrm{~K}$ at atmospheric pressure, using a Karl Fischer coulometer. From these data, the thermodynamic functions and partial molar solvation quantities such as Gibbs energy, enthalpy, and entropy were determined and compared with the interaction energies in 1:1 water-fluoroalkane complexes in vacuum, obtained using B3LYP/6-311++G(d,p). The experimental solubility data indicates a significant specific interaction between the water and the $\alpha-(\omega-)$ substitute atom $(\mathrm{H}, \mathrm{I}, \mathrm{Br}$, or $\mathrm{Cl})$ in the fluoroalkanes.
\end{abstract}

\section{Introduction}

Most works dealing with interactions refer only to experimental or to theoretical studies. It is obvious that a strategy combining both experiment and theory improves the understanding of fundamental aspects underlying thermodynamic phenomena such as solubility, phase equilibria, and many other thermodynamic properties of increasingly complex systems, which are crucial in their technological application. Recent progress in molecular modeling and in experimental techniques allows the direct observation of molecular structures and leads to an interpretation of physicochemical properties of solutions from the standpoint of microscopic details.

The understanding of the molecular interactions in systems involving fluorocarbon (FC) compounds is essential to a wide range of technological applications. The solvation in fully or partially fluorinated liquids is of particular interest in areas such as separation methods and fluorous-phase organic synthesis, ${ }^{1,2}$ surfactants in supercritical solvents, ${ }^{3}$ substitutes for chlorinated solvents, ${ }^{4}$ environmental probes as dielectric solvents, ${ }^{5}$ and in uranium enrichment. ${ }^{6}$ In biomedical applications, they are used as agents for drug delivery, anti-tumural agents, diagnostic imaging agents, and as in vivo gas carriers in liquid ventilation or blood substitute formulations. ${ }^{7-9}$ The perfluorooctylbromide and perfluorodichlorooctane are replacing the perfluorinated compounds in the formulation of artificial blood substitutes. They are currently used on the Oxygent from Alliance Pharmaceutical Corporation and Oxyfluor from Hemogen, since both allow the development of emulsions with higher concentrations of fluorocarbon compounds, thus increasing their oxygencarrying capability. ${ }^{7}$ This wide range of applications results from the unique properties of fluorocarbons, namely, high capacity for dissolving gases, low surface tension, low viscosity, and outstanding chemical and biological inertness. ${ }^{7}$

Despite the growing interest in fluorinated compounds applications, the understanding of their molecular interactions,

* Corresponding author. Tel: +351-234-370200. Fax: +351-234-

370084. E-mail address: jcoutinho@dq.ua.pt.

$\doteqdot$ Universidade de Aveiro.

$\dagger$ Universidade Fernando Pessoa.

$\S$ Universidade do Porto. their unusual and unexpected liquid-phase behavior, and their extreme physicochemical properties is still poor. ${ }^{10-14}$ There are minimal data covering solubility and phase equilibrium of fluorinated compounds. ${ }^{8,10-25}$ The study of water solubility is of particular interest, since the solvation properties and the molecular interactions of fluorocompounds with water are important to understand the FC-in-water or reversed emulsions formation and aging. ${ }^{9,25-28}$

The objective of the present work is to provide experimental and theoretical information about the unlike water-FC compound molecular interactions and to evaluate the effect of $\alpha-(\omega-$ )fluorine substitution by $\mathrm{H}, \mathrm{Cl}, \mathrm{Br}$, and $\mathrm{I}$ on this interaction. For that purpose, experimental solubility data were precisely measured by Karl Fischer titration of the water in saturated fluorocarbon-rich phases, in a sufficiently large temperature range in order to allow the calculation of the thermodynamic quantities associated with the dissolution. On the other hand, $\mathrm{ab}$ initio interaction energies between fluoroalkanes and water were estimated to obtain the magnitude of the specific $1: 1$ interaction in a vacuum. The vacuum 1:1 complexes formed between water and fluoroalkanes have been studied using a B3LYP model at $6-311++\mathrm{G}(\mathrm{d}, \mathrm{p})$ basis set, applying the counterpoise $(\mathrm{CP})$ method to correct the basis set superposition error (BSSE). The effects of the increase of the carbon chain length and the $\alpha-(\omega-)$ substitution of fluorine by $\mathrm{H}, \mathrm{Cl}, \mathrm{Br}$, and I were investigated and will be discussed.

\section{Experimental Section}

Materials. The chemicals used for the measurements were $n$-perfluorohexane $\left(\mathrm{C}_{6} \mathrm{~F}_{14}\right), n$-perfluorooctane $\left(\mathrm{C}_{8} \mathrm{~F}_{18}\right)$, and $n$ perfluorononane $\left(\mathrm{C}_{9} \mathrm{~F}_{20}\right)$ from Fluorochem with purities verified by gas chromatography (GC) of $99.11,98.36$, and $99.18 \mathrm{wt} \%$, respectively, and perfluoroheptane $\left(\mathrm{C}_{7} \mathrm{~F}_{16}\right)$ from Apollo Scientific with a purity of 99.92 wt $\%$ (mixture of isomers). The substituted fluorocompounds $1 \mathrm{Br}$-perfluorooctane $\left(\mathrm{C}_{8} \mathrm{~F}_{17} \mathrm{Br}\right)$, 1H-perfluorooctane $\left(\mathrm{C}_{8} \mathrm{~F}_{17} \mathrm{H}\right), 1 \mathrm{H}, 8 \mathrm{H}$-perfluorooctane $\left(\mathrm{C}_{8} \mathrm{~F}_{16} \mathrm{H}_{2}\right)$, and $1 \mathrm{Cl}, 8 \mathrm{Cl}$-perfluorooctane $\left(\mathrm{C}_{8} \mathrm{~F}_{16} \mathrm{Cl}_{2}\right)$ were acquired at Apollo Scientific presenting purities of 99.90, 97.05, 99.05, and 99.99 wt $\%$, respectively. The $1 \mathrm{I}$-perfluorooctane $\left(\mathrm{C}_{8} \mathrm{~F}_{17} \mathrm{I}\right)$ was ac- 


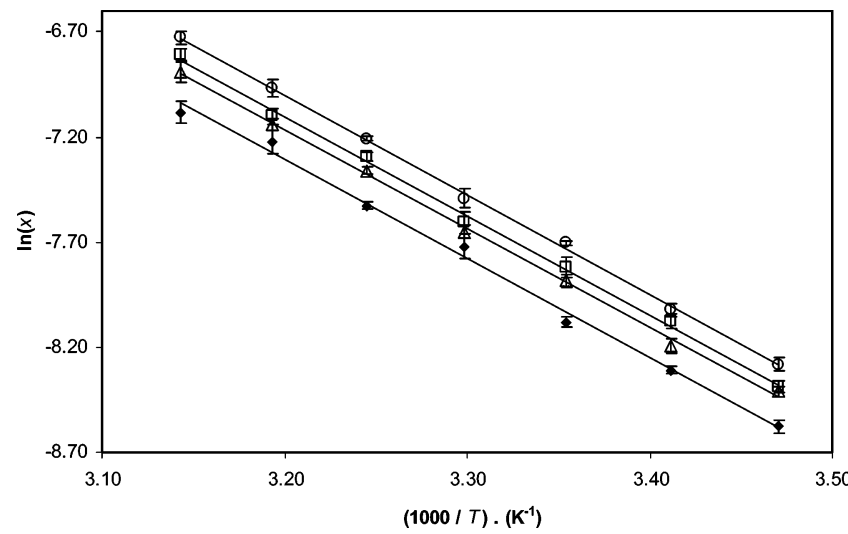

Figure 1. Mole fraction solubility $(x)$ of water in perfluoroalkanes as a function of temperature: $\diamond, \mathrm{C}_{6} \mathrm{~F}_{14} ; \Delta, \mathrm{C}_{7} \mathrm{~F}_{16} ; \square, \mathrm{C}_{8} \mathrm{~F}_{18} ; \mathrm{O}, \mathrm{C}_{9} \mathrm{~F}_{20}$. The solid lines represent the correlation of data using eq 2 for the studied perfluorocarbons.

quired at ABCR with a stated purity of 98.56 wt \%. The $n$-heptane was from Lab-Scan with a purity of $99.34 \mathrm{wt} \%$. Fluorocarbons and $n$-heptane were used as received without any further purification.

The water used was double-distilled, passed by a reverse osmosis system, and further treated with a Milli-Q plus 185 water purification apparatus. It has a resistivity of $18.2 \mathrm{M} \Omega$. $\mathrm{cm}$, a TOC smaller than $5 \mu \mathrm{g} \cdot \mathrm{L}^{-1}$, and is free of particles greater than $0.22 \mu \mathrm{m}$

The analyte used for the coulometric Karl Fischer titration was Hydranal - Coulomat AG from Riedel-de Haën.

Experimental Procedure. The purity of each compound was analyzed by GC with a Varian gas chromatograph CP 3800 with a flame ionization detector (FID). Chromatographic separations were accomplished with a Varian $\mathrm{CP}-\mathrm{Wax} 52 \mathrm{CB}$ column with an internal diameter (i.d.) of $0.53 \mathrm{~mm}$ and equipped with Coating WCot fused silica.

The solubility of water in the FC-rich phase was determined for all the fluorocompounds in the temperature range from 288 to $318 \mathrm{~K}$ with a Metrohm Karl Fischer (KF) coulometer, model 831. The two phases were kept in sealed $22 \mathrm{~mL}$ glass vials. After an initial mixing, the two phases were allowed to rest for $24 \mathrm{~h}$ at the desired temperature. This period was chosen by checking that a complete separation of the two phases was achieved and no further variations in molar fractions were observed, ensuring the saturation of the organic phase by water. The vials were thermostated on an aluminum block immersed in an isolated air bath capable of maintaining the temperature within $\pm 0.01 \mathrm{~K}$ by means of a PID controller inserted in the aluminum block associated with a $\mathrm{Pt} 100$. At least five independent FC phase extractions were performed for each compound at each particular temperature and the respective deviations determined.

Since available data in the literature for $\mathrm{FC}-$ water systems are scarce, ${ }^{15-17}$ the experimental methodology was tested by comparison of the measured values of water in $n$-heptane with literature data, ${ }^{29}$ at the same conditions of temperature and pressure used for the fluorocarbon compounds analysis.

Thermodynamic Functions. The dissolution of a liquid into a liquid is associated with changes in thermodynamics functions, namely, standard Gibbs energy $\left(\Delta_{\mathrm{sol}} G_{m}^{\circ}\right)$, standard enthalpy $\left(\Delta_{\text {sol }} H_{m}^{\circ}\right)$, and standard entropy $\left(\Delta_{\text {sol }} S_{m}^{\circ}\right)$ of solution, which can be calculated from the temperature dependence of the experimental solubility data. These thermodynamic functions are associated with the hypothetical changes that happen in the solute neighborhood when the solute molecules are transferred

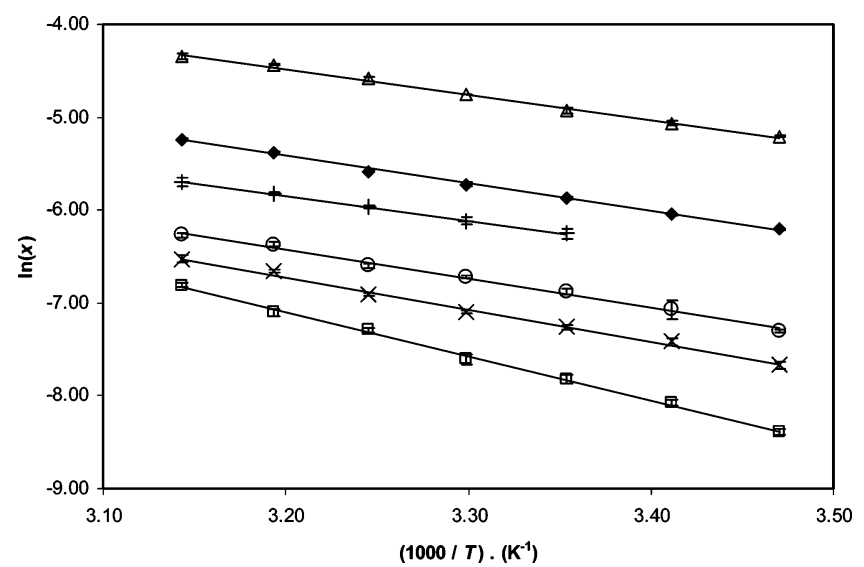

Figure 2. Mole fraction solubility $(x)$ of water in $n$-perfluorooctane and in the substituted $n$-fluorooctanes as a function of temperature: $\square, \mathrm{C}_{8} \mathrm{~F}_{18} ; \times, \mathrm{C}_{8} \mathrm{~F}_{17} \mathrm{Br} ; \mathrm{O}, \mathrm{C}_{8} \mathrm{~F}_{16} \mathrm{Cl}_{2} ;+, \mathrm{C}_{8} \mathrm{~F}_{17} \mathrm{I} ; \diamond, \mathrm{C}_{8} \mathrm{~F}_{17} \mathrm{H} ; \triangle, \mathrm{C}_{8} \mathrm{~F}_{16} \mathrm{H}_{2}$.

to a hypothetical dilute ideal solution where the mole fraction of solute is equal to one, and can be calculated according to the following equations: ${ }^{30}$

$$
\begin{gathered}
\Delta_{\mathrm{sol}} G_{m}^{\circ}=-R T \ln \left(x_{i}\right)_{p} \\
\frac{\Delta_{\mathrm{sol}} H_{m}^{\circ}}{R T^{2}}=\left(\frac{\partial \ln x_{i}}{\partial T}\right)_{p} \\
\Delta_{\mathrm{sol}} S_{m}^{\circ}=R\left[\frac{\partial \ln x_{i}}{\partial \ln T}\right]_{p}
\end{gathered}
$$

where $x_{i}$ is the mole fraction solubility of the solute, $R$ is the ideal gas constant, and $T$ is the temperature at a constant pressure, $p$.

The integration of eq 3 , assuming that $\Delta_{\text {sol }} H_{m}^{\circ}$ is temperature-independent, as was already verified for the solubility of water in normal alkanes from $\mathrm{C}_{7}-\mathrm{C}_{12}$ by calorimetric results, ${ }^{31}$ leads to eq 4 used for the correlation of experimental data, as shown in Figures 1 and 2. In the temperature range from 285

$$
\ln x=A+\frac{B}{T / K}
$$

to $318 \mathrm{~K}$, the calculated standard molar enthalpy of solution is temperature-independent.

Furthermore, the standard molar enthalpy of solution, $\Delta_{\text {sol }} H_{m}^{\circ}$, can be split into two contributions: the standard molar enthalpy of vaporization of the solute, $\Delta_{l}^{\mathrm{g}} H_{m}^{\circ}$, and the standard molar enthalpy of solvation, $\Delta_{\text {svt }} H_{m}^{\circ}$

$$
\Delta_{\mathrm{sol}} H_{m}^{\circ}=\Delta_{\mathrm{svt}} H_{m}^{\circ}+\Delta_{1}^{\mathrm{g}} H_{m}^{\circ}
$$

and it is possible to determine the enthalpy of solvation of a system knowing the enthalpy of solution from experimental solubility data and using the enthalpy of vaporization of the solute.

The standard molar Gibbs function of solvation, $\Delta_{\mathrm{svt}} G_{m}^{\circ}(T)$, can be derived for a temperature $T$ using the hypothetical reference state for the water, in the gas phase and at the standard pressure $p^{\circ}=10^{5} \mathrm{~Pa}$.

$$
\begin{gathered}
\Delta_{\mathrm{svt}} G_{m}^{\circ}(T)=\Delta_{\mathrm{sol}} G_{m}^{\circ}(T)+R T \ln \left(\frac{p(\mathrm{~s} 2, T)}{p^{\circ}}\right) \\
\Delta_{\mathrm{svt}} S_{m}^{\circ}(T)=\frac{\Delta_{\mathrm{svt}} H_{m}^{\circ}(T)-\Delta_{\mathrm{svt}} G_{m}^{\circ}(T)}{T}
\end{gathered}
$$


TABLE 1: Experimental Solubilities in Mole Fraction, $x$, of Water in $\boldsymbol{n}$-heptane and in the Studied Fluorocompounds

\begin{tabular}{|c|c|c|c|c|c|}
\hline$T / \mathrm{K}$ & $\begin{array}{c}\mathrm{C}_{7} \mathrm{H}_{16} \\
10^{4}\left(x \pm \sigma^{a}\right)\end{array}$ & $\begin{array}{c}\mathrm{C}_{6} \mathrm{~F}_{14} \\
10^{4}\left(x \pm \sigma^{a}\right)\end{array}$ & $\begin{array}{c}\mathrm{C}_{7} \mathrm{~F}_{16} \\
10^{4}\left(x \pm \sigma^{a}\right)\end{array}$ & $\begin{array}{c}\mathrm{C}_{8} \mathrm{~F}_{18} \\
10^{4}\left(x \pm \sigma^{a}\right)\end{array}$ & $\begin{array}{c}\mathrm{C}_{9} \mathrm{~F}_{20} \\
10^{4}\left(x \pm \sigma^{a}\right)\end{array}$ \\
\hline 288.15 & $2.9 \pm 0.1$ & $1.88 \pm 0.06$ & $2.23 \pm 0.05$ & $2.27 \pm 0.06$ & $2.53 \pm 0.08$ \\
\hline 293.15 & $3.84 \pm 0.08$ & $2.46 \pm 0.04$ & $2.8 \pm 0.1$ & $3.1 \pm 0.1$ & $3.3 \pm 0.1$ \\
\hline 298.15 & $4.96 \pm 0.04$ & $3.10 \pm 0.07$ & $3.8 \pm 0.1$ & $4.0 \pm 0.2$ & $4.51 \pm 0.04$ \\
\hline 303.15 & $6.2 \pm 0.1$ & $4.4 \pm 0.3$ & $4.7 \pm 0.1$ & $5.0 \pm 0.3$ & $5.4 \pm 0.3$ \\
\hline 308.15 & $7.80 \pm 0.06$ & $5.4 \pm 0.1$ & $6.4 \pm 0.1$ & $6.8 \pm 0.1$ & $7.41 \pm 0.06$ \\
\hline 313.15 & $9.3 \pm 0.2$ & $7.3 \pm 0.4$ & $7.9 \pm 0.2$ & $8.2 \pm 0.3$ & $9.6 \pm 0.4$ \\
\hline 318.15 & $11.5 \pm 0.1$ & $8.4 \pm 0.4$ & $10.2 \pm 0.5$ & $11.0 \pm 0.3$ & $12.0 \pm 0.4$ \\
\hline$T / \mathrm{K}$ & $\begin{array}{c}\mathrm{C}_{8} \mathrm{~F}_{17} \mathrm{H} \\
10^{3}\left(x \pm \sigma^{a}\right)\end{array}$ & $\begin{array}{c}\mathrm{C}_{8} \mathrm{~F}_{16} \mathrm{H}_{2} \\
10^{3}\left(x \pm \sigma^{a}\right)\end{array}$ & $\begin{array}{c}\mathrm{C}_{8} \mathrm{~F}_{16} \mathrm{Cl}_{2} \\
10^{4}\left(x \pm \sigma^{a}\right)\end{array}$ & $\begin{array}{c}\mathrm{C}_{8} \mathrm{~F}_{17} \mathrm{Br} \\
10^{4}\left(x \pm \sigma^{a}\right)\end{array}$ & $\begin{array}{c}\mathrm{C}_{8} \mathrm{~F}_{17} \mathrm{I} \\
10^{3}\left(x \pm \sigma^{a}\right)\end{array}$ \\
\hline 288.15 & $2.02 \pm 0.01$ & $5.49 \pm 0.05$ & $6.74 \pm 0.07$ & $4.7 \pm 0.2$ & \\
\hline 293.15 & $2.37 \pm 0.02$ & $6.3 \pm 0.1$ & $8.5 \pm 0.9$ & $6.0 \pm 0.2$ & \\
\hline 298.15 & $2.82 \pm 0.04$ & $7.3 \pm 0.2$ & $10.3 \pm 0.4$ & $7.0 \pm 0.2$ & $1.9 \pm 0.1$ \\
\hline 303.15 & $3.27 \pm 0.08$ & $8.59 \pm 0.03$ & $12.1 \pm 0.2$ & $8.2 \pm 0.1$ & $2.20 \pm 0.09$ \\
\hline 308.15 & $3.77 \pm 0.03$ & $10.2 \pm 0.2$ & $13.6 \pm 0.4$ & $10.0 \pm 0.2$ & $2.56 \pm 0.03$ \\
\hline 313.15 & $4.62 \pm 0.06$ & $11.9 \pm 0.1$ & $17.1 \pm 0.4$ & $12.8 \pm 0.3$ & $2.96 \pm 0.04$ \\
\hline 318.15 & $5.30 \pm 0.04$ & $13.0 \pm 0.5$ & $18.9 \pm 0.5$ & $14.7 \pm 0.5$ & $3.4 \pm 0.2$ \\
\hline
\end{tabular}

${ }^{a}$ Standard deviation.

where $p(\mathrm{~s} 2, T)$ is the vapor pressure of the solute at the temperature $T$ and $p^{\circ}$ is the standard pressure of $10^{5} \mathrm{~Pa}$.

The thermodynamics functions presented above deal with solvation at a macroscopic level, while the solvation is a molecular process, dependent upon local, rather than macroscopic, properties of the system. Another approach to define a standard state could be based on statistical mechanical methods as proposed by Ben-Naim. ${ }^{32}$ The changes that occur in the solute neighborhood during the dissolution process due to the transfer of one solute molecule of water from a fixed position in an ideal gas phase into a fixed position in the organic solvent fluid, at a constant temperature, $T$, and constant pressure, $p$, with the composition of the system unchanged, are represented by the local standard Gibbs energy, $\Delta_{\mathrm{svt}} G_{m}^{*}$, the local standard enthalpy, $\Delta_{\text {svt }} H_{m}^{*}$, and the local standard entropy, $\Delta_{\mathrm{svt}} S_{m}^{*}$, of solvation. ${ }^{32-34}$ These local standard thermodynamic functions were determined as follows:

$$
\begin{gathered}
\Delta_{\mathrm{svt}} G_{m}^{*}=\Delta_{\mathrm{sol}} G_{m}^{\circ}-R T \ln \left(\frac{R T}{p V_{\mathrm{m}}}\right) \\
\Delta_{\mathrm{svt}} H_{m}^{*}=\Delta_{\mathrm{sol}} H_{m}^{\circ}-R T(T \alpha-1) \\
\Delta_{\mathrm{svt}} S_{m}^{*}=\Delta_{\mathrm{sol}} S_{m}^{\circ}+R \ln \left(\frac{R T}{p V_{\mathrm{m}}}\right)-R(T \alpha-1)
\end{gathered}
$$

where $V_{\mathrm{m}}$ is the molar volume of the solvent and $\alpha$ is the isobaric thermal expansibility of the solvent derived from experimental density data. ${ }^{35-41}$

\section{Results}

Experimental Data. The experimental method was validated by measuring the water solubility in $n$-heptane. Table 1 reports the solubility for water in $n$-heptane at several temperatures and the respective standard deviations. To evaluate the accuracy of the experimental technique used, the solubilities of water in $n$-heptane were compared with literature values. A good agreement with the correlation of different experimental literature data reported by Tsonopoulos ${ }^{29}$ was achieved. The solubility mole fraction values presented in this work have standard deviations inferior to $4 \%$ relative to the literature values.

The solubility of water in the $\mathrm{C}_{6}-\mathrm{C}_{9} n$-perfluroalkanes and in the substituted $n$-fluoroalkanes $\left(\mathrm{C}_{8} \mathrm{~F}_{17} \mathrm{H}, \mathrm{C}_{8} \mathrm{~F}_{16} \mathrm{H}_{2}, \mathrm{C}_{8} \mathrm{~F}_{16} \mathrm{Cl}_{2}\right.$, $\mathrm{C}_{8} \mathrm{~F}_{17} \mathrm{Br}$, and $\mathrm{C}_{8} \mathrm{~F}_{17} \mathrm{I}$ ) was measured from 288 to $318 \mathrm{~K}$ at
TABLE 2: Parameters for the Correlation of the Solubility, $\boldsymbol{x}$, of Water in the Fluorocompounds Using Eq 4

\begin{tabular}{ccc}
\hline solvent & $A \pm \sigma^{a}$ & $10^{-3}\left(B \pm \sigma^{a}\right) / \mathrm{K}$ \\
\hline $\mathrm{C}_{7} \mathrm{H}_{16}$ & $6.43 \pm 0.21$ & $-4.19 \pm 0.06$ \\
$\mathrm{C}_{6} \mathrm{~F}_{14}$ & $7.81 \pm 0.49$ & $-4.72 \pm 0.15$ \\
$\mathrm{C}_{7} \mathrm{~F}_{16}$ & $7.89 \pm 0.27$ & $-4.71 \pm 0.08$ \\
$\mathrm{C}_{8} \mathrm{~F}_{18}$ & $8.03 \pm 0.44$ & $-4.73 \pm 0.10$ \\
$\mathrm{C}_{9} \mathrm{~F}_{20}$ & $8.24 \pm 0.45$ & $-4.76 \pm 0.14$ \\
$\mathrm{C}_{8} \mathrm{~F}_{17} \mathrm{H}$ & $4.05 \pm 0.29$ & $-2.96 \pm 0.09$ \\
$\mathrm{C}_{8} \mathrm{~F}_{16} \mathrm{H}_{2}$ & $4.28 \pm 0.24$ & $-2.74 \pm 0.07$ \\
$\mathrm{C}_{8} \mathrm{~F}_{16} \mathrm{Cl}_{2}$ & $3.60 \pm 0.37$ & $-3.13 \pm 0.11$ \\
$\mathrm{C}_{8} \mathrm{~F}_{17} \mathrm{Br}$ & $4.38 \pm 0.54$ & $-3.47 \pm 0.16$ \\
$\mathrm{C}_{8} \mathrm{~F}_{17} \mathrm{I}$ & $2.75 \pm 0.08$ & $-2.69 \pm 0.03$ \\
${ }^{a}$ Standard deviation. &
\end{tabular}

atmospheric pressure. Experimental values for the solubility of water in the studied $n$-perfluoroalkanes and substituted $n$ fluorooctanes and the respective standard deviations are reported in Table 1 and presented in Figures 1 and 2, respectively. It should be noted that the solubility of water in $n$-heptane is higher than in the fully fluorinated FCs, even though the latter have smaller surface tensions and larger molar volumes. It can be seen that the water solubility in $n$-perfluoroalkanes is strongly dependent on the temperature and only weakly dependent on the number of carbons. The solubility of water in the $\alpha-(\omega-)$ substituted fluorocarbons increases with the inclusion of the heteroatoms, according to the sequence $\mathrm{F}<\mathrm{Br}<(\mathrm{Cl})_{2}<\mathrm{I}<$ $\mathrm{H}<(\mathrm{H})_{2}$, reaching an increase of 1 order of magnitude with the inclusion of one or two hydrogen atoms or one iodine atom. The water solubility in $\alpha-(\omega$-)substituted fluorocarbons increases with the decreasing electronegativity of the heteroatom due to the formation of a dipole that enhances the interactions with polar molecules such as water. The apparent exception of the chlorinated fluoroalkane is due to the disubstitution that enhances the water solubility, as also happens with the introduction of two hydrogens in fluorooctane compared to the single substitution. Although not performed due to the commercial nonavailability of the $\mathrm{C}_{8} \mathrm{~F}_{17} \mathrm{Cl}$, it is safe to assume that the water solubility in this compound would be inferior to the solubility in $\mathrm{C}_{8} \mathrm{~F}_{17} \mathrm{Br}$. These results also explain the enhanced stability of the perfluorooctylbromide and perfluorodichlorooctane emulsions and why these compounds are replacing perfluorooctane in blood substitute formulations.

To calculate the associated thermodynamic functions of solution, eq 4 was used to correlate the temperature dependence of the solubility data for the studied systems. The fitted $A$ and $B$ parameters as well as their standard deviations are reported in Table $2 .{ }^{42}$

The conventional standard molar enthalpy, Gibbs energy, and entropy of solution are reported in Table 3. From the experimental entropies of solution of water in the $n$-perfluoroalkanes, a small entropic increment of $+1.4 \mathrm{~J} \cdot \mathrm{K}^{-1} \cdot \mathrm{mol}^{-1}$ per carbon number $(\mathrm{CN})$ can be derived. This entropic increment per $\mathrm{CN}$ produces a small contribution to the increase in the solubility per $\mathrm{CN}$ in the $n$-perfluoroalkanes.

The conventional standard molar enthalpies of solvation, $\Delta_{\text {svt }} H_{m}^{\circ}$, were derived using the reported ${ }^{43}$ standard molar enthalpy of vaporization of $\mathrm{H}_{2} \mathrm{O}$ at $298.15 \mathrm{~K}, \Delta_{1}^{\mathrm{g}} H_{m}^{\circ}(298.15$ $\mathrm{K}), 43.99 \mathrm{~kJ} \cdot \mathrm{mol}^{-1}$, and the Ben-Naim standard quantities of solvation were derived using the molar volume and the isobaric thermal expansibility of the solvents derived from experimental density data. ${ }^{35-41}$ The conventional molar enthalpy of solution of water in $n$-heptane obtained in this work, $(34.9 \pm 0.5)$ $\mathrm{kJ} \cdot \mathrm{mol}^{-1}$, is in excellent agreement with literature calorimetric measurements reported to be $(34.9 \pm 1.1) \mathrm{kJ} \cdot \mathrm{mol}^{-1}$ at $298 \mathrm{~K} .{ }^{31}$ 
TABLE 3: Thermodynamic Conventional Properties of the Solution and Solvation of Water in the Organic Compounds Studied at $298.15 \mathrm{~K}$

\begin{tabular}{|c|c|c|c|c|c|c|}
\hline solvent & $\begin{array}{c}\left(\Delta_{\mathrm{sol}} G_{m}^{\circ} \pm \sigma^{a}\right) / \\
\mathrm{kJ} \cdot \mathrm{mol}^{-1}\end{array}$ & $\begin{array}{c}\left(\Delta_{\text {sol }} H_{m}^{\circ} \pm \sigma^{a}\right) / \\
\mathrm{kJ} \cdot \mathrm{mol}^{-1}\end{array}$ & $\begin{array}{c}\left(\Delta_{\mathrm{sol}} S_{m}^{\circ} \pm \sigma^{a}\right) / \\
\mathrm{kJ} \cdot \mathrm{mol}^{-1}\end{array}$ & $\begin{array}{c}\left(\Delta_{\text {svt }} G_{m}^{\circ} \pm \sigma^{a}\right) / \\
\mathrm{kJ} \cdot \mathrm{mol}^{-1}\end{array}$ & $\begin{array}{c}\left(\Delta_{\text {svt }} H_{m}^{\circ} \pm \sigma^{a}\right) / \\
\mathrm{kJ} \cdot \mathrm{mol}^{-1}\end{array}$ & $\begin{array}{c}\left(\Delta_{\text {svt }} S_{m}^{\circ} \pm \sigma^{a}\right) / \\
\mathrm{kJ} \cdot \mathrm{mol}^{-1}\end{array}$ \\
\hline $\mathrm{C}_{7} \mathrm{H}_{16}$ & $18.86 \pm 0.02$ & $34.9 \pm 0.5$ & $53.6 \pm 1.8$ & $10.30 \pm 0.02$ & $-9.1 \pm 0.5$ & $-65.2 \pm 1.8$ \\
\hline $\mathrm{C}_{6} \mathrm{~F}_{14}$ & $20.03 \pm 0.06$ & $39.3 \pm 1.2$ & $64.5 \pm 4.2$ & $11.47 \pm 0.06$ & $-4.7 \pm 1.2$ & $-54.3 \pm 4.2$ \\
\hline $\mathrm{C}_{7} \mathrm{~F}_{16}$ & $19.55 \pm 0.07$ & $39.1 \pm 0.6$ & $65.6 \pm 2.3$ & $10.99 \pm 0.07$ & $-4.9 \pm 0.7$ & $-53.2 \pm 2.3$ \\
\hline $\mathrm{C}_{8} \mathrm{~F}_{18}$ & $19.39 \pm 0.12$ & $39.3 \pm 0.8$ & $66.8 \pm 2.8$ & $10.83 \pm 0.12$ & $-4.7 \pm 0.8$ & $-52.0 \pm 2.8$ \\
\hline $\mathrm{C}_{9} \mathrm{~F}_{20}$ & $19.10 \pm 0.07$ & $39.6 \pm 1.1$ & $68.8 \pm 3.8$ & $10.54 \pm 0.07$ & $-4.4 \pm 1.1$ & $-50.1 \pm 3.8$ \\
\hline $\mathrm{C}_{8} \mathrm{~F}_{17} \mathrm{H}$ & $14.55 \pm 0.03$ & $24.6 \pm 0.7$ & $33.7 \pm 2.4$ & $5.99 \pm 0.03$ & $-19.4 \pm 0.7$ & $-85.1 \pm 2.4$ \\
\hline $\mathrm{C}_{8} \mathrm{~F}_{16} \mathrm{H}_{2}$ & $12.21 \pm 0.08$ & $22.8 \pm 0.6$ & $35.4 \pm 2.1$ & $3.65 \pm 0.08$ & $-21.2 \pm 0.6$ & $-83.5 \pm 2.1$ \\
\hline $\mathrm{C}_{8} \mathrm{~F}_{16} \mathrm{Cl}_{2}$ & $17.05 \pm 0.09$ & $26.0 \pm 0.9$ & $30.1 \pm 3.2$ & $8.49 \pm 0.09$ & $-18.0 \pm 0.9$ & $-88.7 \pm 3.2$ \\
\hline $\mathrm{C}_{8} \mathrm{~F}_{17} \mathrm{Br}$ & $18.00 \pm 0.06$ & $28.9 \pm 1.4$ & $36.4 \pm 4.6$ & $9.43 \pm 0.06$ & $-15.1 \pm 1.4$ & $-80.4 \pm 4.6$ \\
\hline $\mathrm{C}_{8} \mathrm{~F}_{17} \mathrm{I}$ & $15.51 \pm 0.13$ & $22.3 \pm 0.2$ & $22.9 \pm 0.9$ & $6.95 \pm 0.13$ & $-21.6 \pm 0.2$ & $-95.9 \pm 0.9$ \\
\hline
\end{tabular}

${ }^{a}$ Standard deviation.

TABLE 4: Thermodynamic Local Standard Properties of the Solvation of Water in the Organic Compounds Studied at 298.15 K

\begin{tabular}{|c|c|c|c|c|c|c|}
\hline solvent & $\gamma / \mathrm{J} \cdot \mathrm{m}^{-2}$ & $\begin{array}{c}10^{4} V_{m} / \\
\mathrm{m}^{3} \cdot \mathrm{mol}^{-1}\end{array}$ & $\begin{array}{l}10^{3} \alpha / \\
\mathrm{K}^{-1}\end{array}$ & $\begin{array}{c}\left(\Delta_{\mathrm{svt}} G_{m}^{*} \pm \sigma^{a}\right) / \\
\mathrm{J} \cdot \mathrm{K}^{-1} \cdot \mathrm{mol}^{-1}\end{array}$ & $\begin{array}{c}\left(\Delta_{\mathrm{svt}} H_{m}^{*} \pm \sigma^{a}\right) / \\
\mathrm{J} \cdot \mathrm{K}^{-1} \cdot \mathrm{mol}^{-1}\end{array}$ & $\begin{array}{c}\left(\Delta_{\mathrm{svv}} S_{m}^{*} \pm \sigma^{a}\right) / \\
\mathrm{J} \cdot \mathrm{K}^{-1} \cdot \mathrm{mol}^{-1}\end{array}$ \\
\hline $\mathrm{C}_{7} \mathrm{H}_{16}$ & $19.7^{45}$ & $1.47^{39}$ & $1.26^{39}$ & $-2.40 \pm 0.02$ & $-7.59 \pm 0.5$ & $-17.4 \pm 1.8$ \\
\hline $\mathrm{C}_{6} \mathrm{~F}_{14}$ & $12.2^{44}$ & $2.02^{36}$ & $1.80^{36}$ & $-0.46 \pm 0.06$ & $-3.57 \pm 1.2$ & $-10.5 \pm 4.2$ \\
\hline $\mathrm{C}_{7} \mathrm{~F}_{16}$ & $13.6^{44}$ & $2.24^{35}$ & $1.62^{35}$ & $-0.67 \pm 0.07$ & $-3.59 \pm 0.7$ & $-9.8 \pm 2.3$ \\
\hline $\mathrm{C}_{8} \mathrm{~F}_{18}$ & $14.5^{44}$ & $2.48^{37}$ & $1.51^{37}$ & $-0.58 \pm 0.12$ & $-3.30 \pm 0.8$ & $-9.1 \pm 2.8$ \\
\hline $\mathrm{C}_{9} \mathrm{~F}_{20}$ & $15.4^{44}$ & $2.73^{36}$ & $1.39^{36}$ & $-0.64 \pm 0.07$ & $-2.94 \pm 1.1$ & $-7.7 \pm 3.8$ \\
\hline $\mathrm{C}_{8} \mathrm{~F}_{17} \mathrm{H}$ & & $2.40^{36}$ & $1.38^{36}$ & $-5.51 \pm 0.03$ & $-17.9 \pm 0.7$ & $-41.7 \pm 2.4$ \\
\hline $\mathrm{C}_{8} \mathrm{~F}_{16} \mathrm{H}_{2}$ & & $2.29^{38}$ & $1.27^{38}$ & $-7.96 \pm 0.08$ & $-19.7 \pm 0.6$ & $-39.3 \pm 2.1$ \\
\hline $\mathrm{C}_{8} \mathrm{~F}_{16} \mathrm{Cl}_{2}$ & & $2.62^{41}$ & $1.26^{b}$ & $-2.80 \pm 0.09$ & $-16.4 \pm 0.9$ & $-45.6 \pm 3.2$ \\
\hline $\mathrm{C}_{8} \mathrm{~F}_{17} \mathrm{Br}$ & $17.4^{44}$ & $2.60^{36}$ & $1.26^{36}$ & $-1.86 \pm 0.06$ & $-13.6 \pm 1.4$ & $-39.3 \pm 4.6$ \\
\hline $\mathrm{C}_{8} \mathrm{~F}_{17} \mathrm{I}$ & & $2.68^{40}$ & $1.23^{b}$ & $-4.28 \pm 0.13$ & $-20.1 \pm 0.2$ & $-53.0 \pm 0.9$ \\
\hline
\end{tabular}

${ }^{a}$ Standard deviation. ${ }^{b}$ Obtained from the molar volume temperature dependence of $\mathrm{C}_{8} \mathrm{~F}_{17} \mathrm{Br}$ in the absence of experimental data.

The standard molar enthalpies of solution of water in the $n$-perfluoroalkanes also do not show any dependence on the carbon number and are somewhat higher in $n$-perfluoroalkanes than in the respective $n$-alkanes with a value of $(39.3 \pm 0.2)$ $\mathrm{kJ} \cdot \mathrm{mol}^{-1}$. A significant decrease in the standard molar enthalpy of solution of the water in $\alpha$ - $(\omega)$-substituted $n$-fluorooctanes was observed when compared with $n$-perfluorooctane. This indicates that less energy is necessary to supply for the solubility of $\mathrm{H}_{2} \mathrm{O}$ in a substituted fluoroalkane than to the respective perfluroalkane compound. This effect is best visualized using the Ben-Naim local standard thermodynamic functions of the solvation of water at $298.15 \mathrm{~K}$. The Ben-Naim local standard Gibbs energy, enthalpy, and entropy changes along with the molar volume, the thermal expansion coefficient, and the surface tension of the liquids at $298.15 \mathrm{~K}$ are reported in Table 4. ${ }^{35-41,44-45}$ The uncertainty interval quoted is the standard deviation of each independent function determination. ${ }^{42}$

Although the values reported show that, under the Ben-Naim local standard functions, the Gibbs energy change of solvation is always negative, and thus the solvation process is spontaneous, for the perfluoroalkanes this value is very small and close to zero compared with the values reported for the alkane and the substituted fluoroalkanes. This shows that the interactions between the perfluorocarbon and the water are negligible compared to those observed in the alkanes ${ }^{46}$ and substituted fluoroalkanes. The Ben-Naim standard enthalpies of solvation show that the solvation is favorable because the enthalpy changes overwhelm the entropy changes. From their values, it is still more apparent that a strong interaction between the water and the substituted fluoroalkanes exists, in opposition to what can be observed for the perfluoroalkanes where this interaction is very small. The values observed for the $n$-heptane, in good agreement with those of Graziano, ${ }^{46}$ show that for the alkanes a significant interaction between the water and the alkane molecule appears. This is removed by the replacement of the hydrogen atoms for the more electronegative fluorine in perfluoroalkanes and reinforced by the replacement of a fluorine by a less electronegative atom in the substituted fluoroalkanes.

The following order was observed for the local standard molar enthalpies of solvation:

$$
\mathrm{C}_{8} \mathrm{~F}_{18} \ll \mathrm{C}_{8} \mathrm{~F}_{17} \mathrm{Br}<\mathrm{C}_{8} \mathrm{~F}_{16} \mathrm{Cl}_{2}<\mathrm{C}_{8} \mathrm{~F}_{17} \mathrm{H}<\mathrm{C}_{8} \mathrm{~F}_{16} \mathrm{H}_{2}<\mathrm{C}_{8} \mathrm{~F}_{17} \mathrm{I}
$$

On the basis of the experimental standard molar or on the local standard molar enthalpies of solvation, it can be observed that the replacement of an $\alpha$ - $(\omega$-)fluorine by another atom leads to stronger enthalpic interactions between the fluorinated compound and water, increasing the standard molar enthalpies of solvation by -10 to $-15 \mathrm{~kJ} \cdot \mathrm{mol}^{-1}$. A difference of about $10 \%$ in the molar enthalpy of solvation of water in the $\alpha-(\omega-)$ substituted $n$-fluorooctane, $\mathrm{C}_{8} \mathrm{~F}_{16} \mathrm{H}_{2}$, was noticed when compared with the monosubstituted fluoroalkane $\mathrm{C}_{8} \mathrm{~F}_{17} \mathrm{H}$.

In accordance with the expected entropy decrease associated with the 1:1 specific interaction, the substituted $n$-fluorooctanes have significantly higher negative values for the molar entropies of solvation of water, $\Delta_{\text {svt }} S_{m}^{\circ}$ and $\Delta_{\text {svt }} S_{m}^{*}$, than the $n$-perfluorooctane, as a consequence of the decrease of degrees of freedom in the two interacting molecules. The entropy of the solvation of water in $\mathrm{C}_{8} \mathrm{~F}_{16} \mathrm{H}_{2}$ is of the same order of magnitude as the monosubstituted $\mathrm{C}_{8} \mathrm{~F}_{17} \mathrm{H}$, indicating identical solvation interactions in the mono- and disubstituted fluoroalkanes.

Ab Initio Calculations. Ab Initio calculations were performed in order to evaluate the magnitude of the interaction energies between fluoroalkanes and water. The complexes formed between water and fluoroalkanes have been studied in a 1:1 interaction model in the gas phase. This information was found to be very useful to understand and support the proposed interpretation of the experimental data. Gaussian $03 \mathrm{~W}$ program package revision B. $03^{47}$ was used in all the calculations. The 

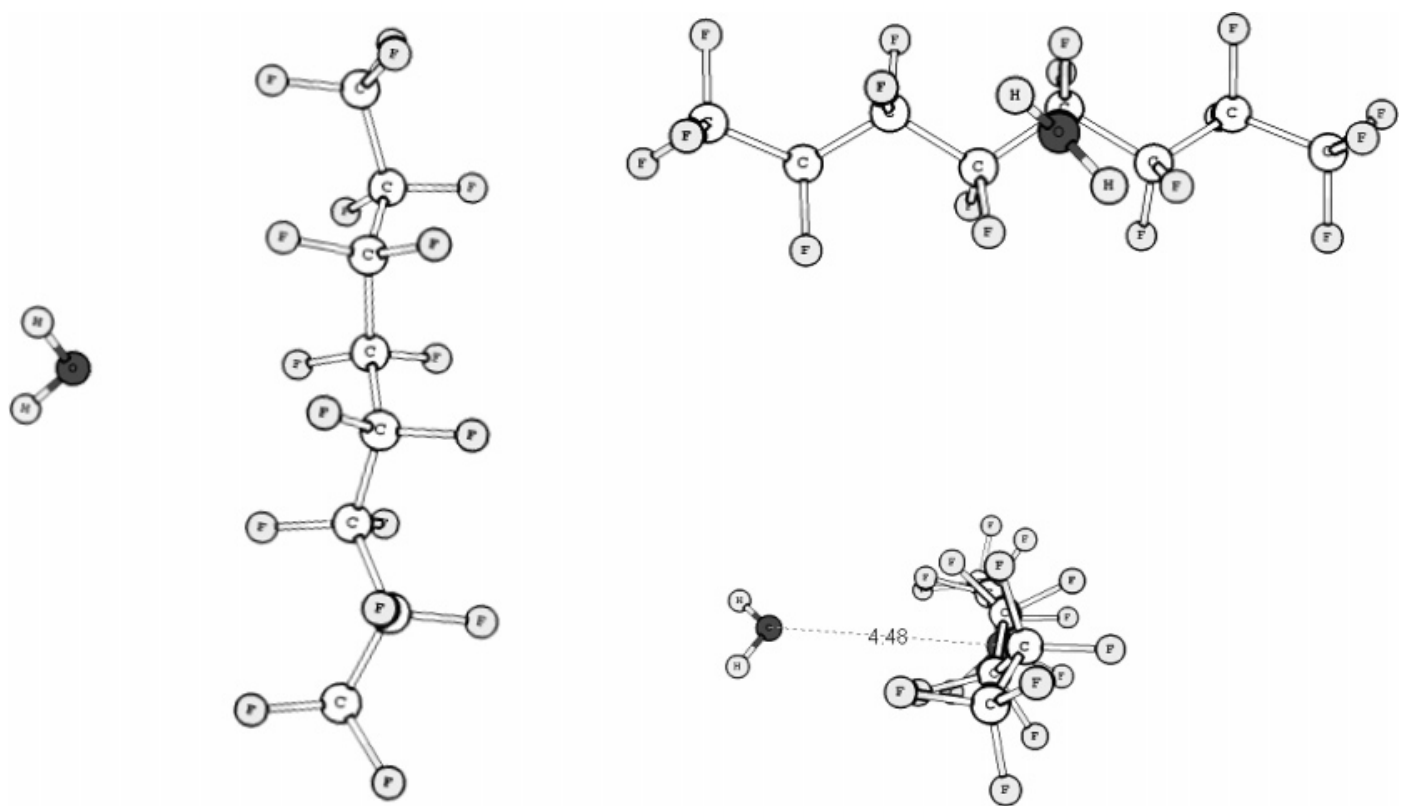

Figure 3. Schematic views of the structure representation for the $n$-perfluorooctane-water complex. Geometry obtained at the B3LYP/6-311++G$(\mathrm{d}, \mathrm{p})$ level of theory. Distances are in angstroms $(\AA)$.

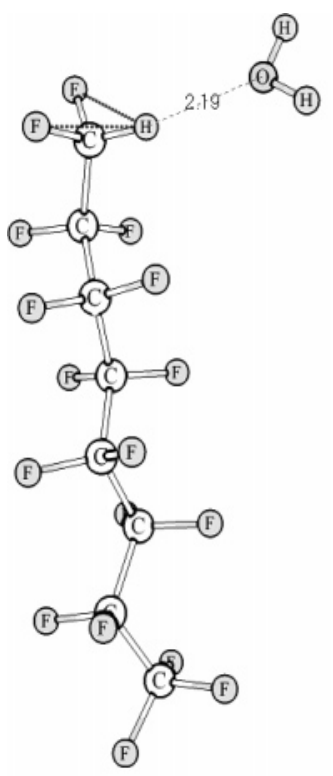

A

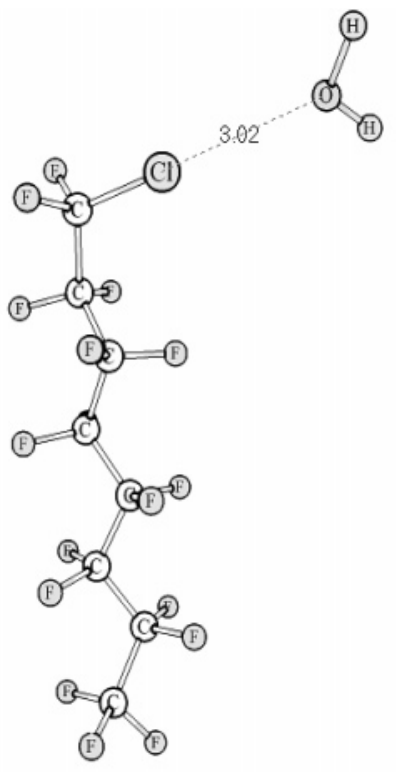

B

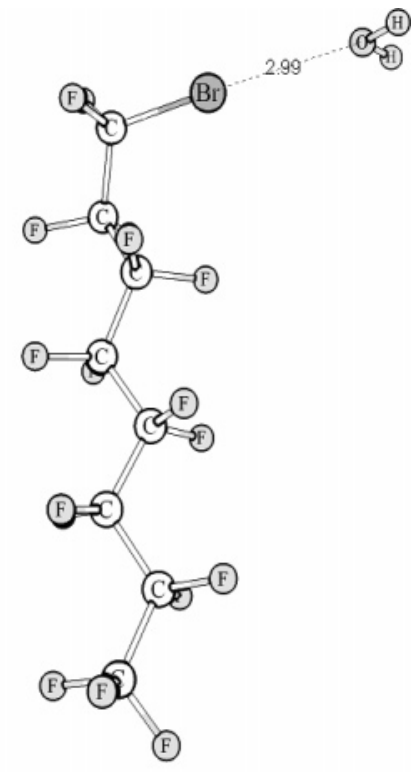

C

Figure 4. Schematic structure representation of the optimized geometries for the substituted fluorooctane-water complex at the B3LYP/6-311++G(d,p) level of theory. (A), $\mathrm{C}_{8} \mathrm{~F}_{17} \mathrm{H}-\mathrm{H}_{2} \mathrm{O}$; (B), $\mathrm{C}_{8} \mathrm{~F}_{17} \mathrm{Cl}-\mathrm{H}_{2} \mathrm{O}$; (C), $\mathrm{C}_{8} \mathrm{~F}_{17} \mathrm{Br}-\mathrm{H}_{2} \mathrm{O}$. Distances are in angstroms $(\AA)$.

molecular structures were fully optimized at the B3LYP/6$311++\mathrm{G}(\mathrm{d}, \mathrm{p})$ level of theory. The basis set superposition error (BSSE) correction was estimated by the counterpoise (CP) calculation using the COUNTERPOISE option as implemented in Gaussian 03W. All the geometries have been fully optimized without constraints at the same level of theory.

Figure 3 shows the calculated optimized geometry for the gas-phase 1:1 complex between $\mathrm{C}_{8} \mathrm{~F}_{18}$ and $\mathrm{H}_{2} \mathrm{O}$. This structure is representative of all the $n$-perfluoroalkane-water complexes studied in this work. Note that the oxygen atom of the water molecule is turned to the interspaces of the perfluorocarbon molecule, as shown in Figure 3. The dihedral angle $\left(162^{\circ}\right)$ defined by the carbon atoms in the $n$-perfluoroalkane complexes with water is essentially identical to the same dihedral angle obtained in the $n$-perfluoroalkanes alone, showing that the geometries of the $n$-perfluoroalkanes are essentially not disturbed in a 1:1 interaction in the gas phase.

These calculations have also been performed for monoderivatives of $n$-perfluorooctane, $\left(\mathrm{C}_{8} \mathrm{~F}_{18}\right)$, namely, $\mathrm{C}_{7} \mathrm{~F}_{15} \mathrm{CF}_{2} \mathrm{H}$, $\mathrm{C}_{7} \mathrm{~F}_{15} \mathrm{CF}_{2} \mathrm{Cl}$, and $\mathrm{C}_{7} \mathrm{~F}_{15} \mathrm{CF}_{2} \mathrm{Br}$. As the iodine atom is out of the range of the basis set used, the $\mathrm{C}_{7} \mathrm{~F}_{15} \mathrm{CF}_{2} \mathrm{I}$ was not considered in the calculations. A schematic view of the molecular structures of the different water-fluoroalkane complexes is depicted in Figure 4. Contrary to the calculated geometry for $n$-perfluoroalkane-water complexes, where the oxygen atom of the water molecule is turned to the interspaces of the fluorocarbon molecule, in the $\mathrm{C}_{7} \mathrm{~F}_{15} \mathrm{CF}_{2} \mathrm{X}(\mathrm{H}, \mathrm{Cl}, \mathrm{Br})$ to $\mathrm{H}_{2} \mathrm{O}$ complex, the interaction takes place between the oxygen atom of the water 
TABLE 5: Distances between the Oxygen Atom of the Water Molecule and the Substituted Atom in the $n$-Fluoroalkanes $\left(\mathrm{C}_{7} \mathbf{F}_{15} \mathrm{CF}_{2}-\mathrm{X}, \mathrm{H}, \mathrm{Cl}\right.$, and $\left.\mathrm{Br}\right)$ and Some Selected Atomic Charges (Performed by Mulliken Population Analysis) for the $\boldsymbol{n}$-Perfluoroctane and the Substituted $n$-Fluorooctanes ${ }^{a}$

\begin{tabular}{lcccc}
\hline & \multirow{2}{*}{$\begin{array}{c}\text { distance } \\
\mathrm{C}_{7} \mathrm{~F}_{15} \mathrm{CF}_{2} \mathrm{X}\end{array}$} & \multicolumn{3}{c}{ Mulliken charges } \\
\cline { 3 - 5 } $\mathrm{O} \cdots \mathrm{X})(\AA)$ & $\mathrm{C}^{b}$ & $\mathrm{X}$ & \multicolumn{1}{c}{$\mathrm{F}^{c}$} \\
$\mathrm{X}=\mathrm{F}$ & & +0.61 & & $(-0.09)(-0.08)(-0.06)$ \\
$\mathrm{X}=\mathrm{H}$ & 2.19 & +0.20 & +0.29 & $(-0.11)(-0.90)$ \\
$\mathrm{X}=\mathrm{Cl}$ & 3.02 & -0.11 & +0.37 & $(+0.04)(+0.00)$ \\
$\mathrm{X}=\mathrm{Br}$ & 2.99 & +0.32 & +0.13 & $(-0.01)(+0.00)$
\end{tabular}

${ }^{a}$ Results were obtained in gas phase at the B3LYP/6-311++G(d,p) level of theory. ${ }^{b}$ Nearest carbon atom. ${ }^{c}$ Vicinity fluorine atoms.

TABLE 6: Energy Values Obtained for the Studied Compounds in Gas Phase at the B3LYP/6-311++G(d,p) Level of Theory ${ }^{a}$

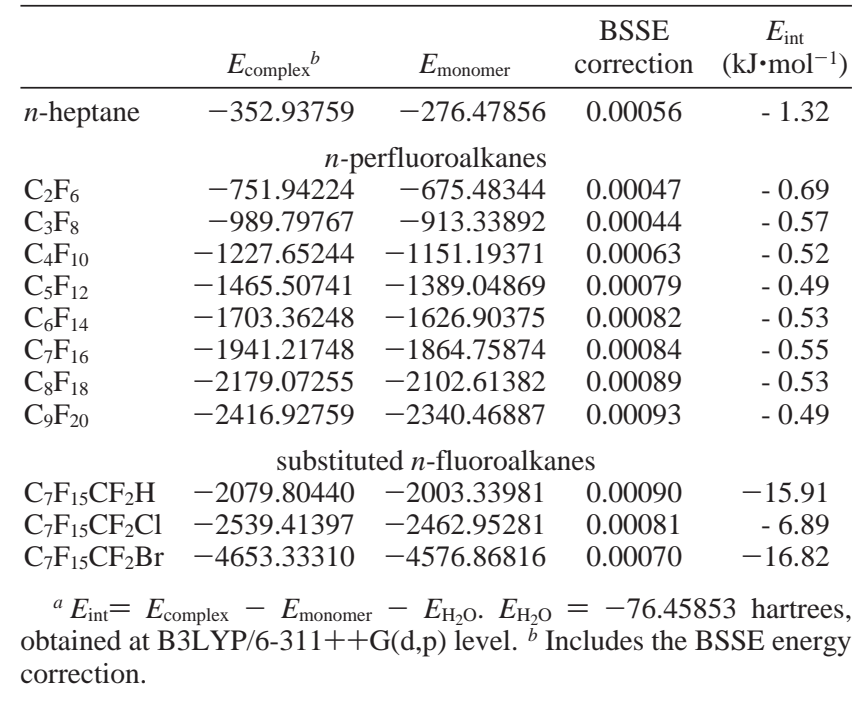

molecule and $\mathrm{X}(\mathrm{H}, \mathrm{Cl}$, or $\mathrm{Br})$ of the perfluorocarbon monoderivatives.

Table 5 lists the results obtained for the distances between the oxygen atom of the water molecule and the substituted atom in the fluoroalkanes $\left(\mathrm{C}_{7} \mathrm{~F}_{15} \mathrm{CF}_{2}-\mathrm{X}, \mathrm{H}, \mathrm{Cl}\right.$, and $\left.\mathrm{Br}\right)$ together with some selected atomic charges, performed by Mulliken population analysis, for the $n$-perfluoroctane and the substituted $n$-fluorooctanes. The substituted atom in the substituted fluoroalkanes $(\mathrm{H}, \mathrm{Cl}$, and $\mathrm{Br})$ exhibits positive charge distribution. This seems to be due to the high electronegativity of the fluorocarbon vicinity and contributes to the observed position and interaction of the water molecule with the substituted atom $(\mathrm{H}, \mathrm{Cl}, \mathrm{Br})$ in the fluoroalkanes.

Gas-phase, 1:1 complex interactions, $E_{\text {int }}$, between water and perfluoroalkanes and fluoroalkanes have been calculated according to the following equation:

$$
E_{\text {int }}=E_{\text {complex }}-E_{\text {monomer }}-E_{\mathrm{H}_{2} \mathrm{O}}
$$

where $E_{\mathrm{H}_{2} \mathrm{O}}, E_{\text {monomer }}$, and $E_{\text {complex }}$ are the total energies obtained, respectively, for the water, for the $n$-perfluoroalkanes or substituted $n$-fluoroalkanes, and for the 1:1 water to perfluoroalkane or water to substituted $n$-fluoroalkane complexes in the gas phase at the B3LYP/6-311++G(d,p) level of theory. The BSSE correction was included in the complex total energy, $E_{\text {complex} \text {. }}$

The total energies obtained for the compounds studied (perfluoroalkanes, from $\mathrm{C}_{2} \mathrm{~F}_{6}$ to $\mathrm{C}_{9} \mathrm{~F}_{20}$, the fluoroalkanes $\mathrm{C}_{8} \mathrm{~F}_{17} \mathrm{H}$, $\mathrm{C}_{8} \mathrm{~F}_{17} \mathrm{Cl}$, and $\mathrm{C}_{8} \mathrm{~F}_{17} \mathrm{Br}$, and $n$-heptane) are reported in Table 6 .
For $n$-perfluoroalkanes, only a very weak interaction $(0.4$ to 0.6) $\mathrm{kJ} \cdot \mathrm{mol}^{-1}$ between the $\mathrm{H}_{2} \mathrm{O}$ and the $n$-perfluoroalkane molecules, ranging from $\mathrm{C}_{2}$ to $\mathrm{C}_{9}$, was observed. As obtained from the experimental data reported in Tables 3 and 4, no dependence of the energies of interaction on the chain length was observed.

For the $\alpha$-substituted fluoroalkanes, both the optimized molecular structures for the complexes shown in Figure 4 and the derived interaction energies, $E_{\mathrm{int}}$, reported in Table 6 indicate the existence of an important interaction between the water molecule and the substituted atom $(\mathrm{H}, \mathrm{Cl}$, or $\mathrm{Br})$ in the $1: 1$ complex. Due to the dipole generated and the positive charge that appears at the substituted atom $(\mathrm{H}, \mathrm{Cl}$, or $\mathrm{Br})$, the interaction will take place between this atom and the oxygen of the water molecule. The calculated interaction energies for the $\alpha-(\omega-)$ substituted fluoroalkanes are -7 to $-17 \mathrm{~kJ} \cdot \mathrm{mol}^{-1}$ higher than for the respective perfluoroalkane where no significant interaction is observed, as shown by the very low values of $E_{\text {int }}$ obtained. For $n$-heptane, an $E_{\text {int }}$ with an intermediate value between those observed for the perfluoroalkanes and their substituted counterparts was estimated as reported in Table 6. These results are in good agreement with those observed experimentally and reported in Table 4.

\section{Discussion}

The experimental solubility data for the solvation of water in fluorocompound solvents indicates that the process is spontaneous under the Ben-Naim standard conditions, due to the negative standard local enthalpy change, as can be seen in Table 4. For the perfluoroalkanes, the low values of local Gibbs energy and enthalpy change of solvation indicate a negligible interaction between water and these molecules, while the higher values observed for the substituted perfluoroalkanes indicate that some favorable interactions are present. For $n$-heptane, an intermediate value of the local interaction enthalpy shows that a favorable interaction between the alkanes and water exists. ${ }^{46}$ From Table 4, it can be seen that the negative standard local enthalpy follows the general trend observed, for the increase of the water solubility indicating that this interaction is driving the solubility.

The calculations performed using the 1:1 energetic interactions in the gas phase were found to be in good agreement with the values of molar enthalpies of solvation derived from the experimental solubility data. The calculated values for the interaction energies support the observation of the experimental data that the replacement of a fluorine atom by another halogen or by hydrogen creates a dipole with a positive charge on the new atom that increases the interaction between the solute and the solvent, thus strongly enhancing the solubility of water on the fluorinated compounds.

The substituent effect in the water solubility in $n$-perfluoroalkanes is driven by the change of the standard local molar enthalpy of solvation of water in the substituted $n$-fluoroalkanes. The increase, relative to the perfluorooctane, on the stabilization energy obtained for the gas-phase interaction between water and $\alpha$-substituted $n$-fluorooctanes using ab initio methods is in good agreement with the increase observed for the local standard molar enthalpies of solvation. This indicates that the interaction between the water molecule and the substituted atom $(\mathrm{H}, \mathrm{Cl}$, or $\mathrm{Br}$ ) in the $n$-fluoroalkane has a major contribution to the overall solvation process explaining why the brominated or chlorinated fluoroalkanes are superior to the corresponding perfluroalkanes in blood substitute formulations. There is a general increase of 1 order of magnitude from the fully perfluoroalkanes to the substituted fluorooctanes both from the 
$a b$ initio calculations and from the standard local enthalpy of solvation. The ab initio calculations also show evidence for the favorable interaction between water and $n$-heptane with the formation of a weak interaction between the hydrocarbon and the water as suggested by Graziano ${ }^{46}$ using the Ben-Naim local standard thermodynamic properties derived from the experimental solubility data.

The experimental data for the Ben-Naim local standard enthalpy of the perfluoroalkanes are in close agreement with the results obtained from the ab initio calculations. However, a slight difference appears in the substituted fluoroalkanes, that may result from the assumption of the 1:1 interaction in the gas phase made in the ab initio calculations and the actual situation in the liquid phase with a much larger coordination number, where some small structural reorganization of solvent molecules upon the insertion of a water molecule may occur, as indicated by the Ben-Naim local standard entropy.

\section{Conclusions}

Original data for the solubility of water in linear fluoroalkanes used in blood substitute formulations at temperatures ranging between 288 and $318 \mathrm{~K}$ and at atmospheric pressure are presented. The temperature range studied allows the derivation of several thermodynamic properties characteristic of the dissolution process that up to now had not been directly determined. The solubility of water within these compounds is fairly insensitive to the carbon number but strongly influenced by the temperature, as a result of the high positive enthalpy of solution.

The water solubility in the $\alpha-(\omega$-)substituted $n$-fluoroalkanes was observed to be higher than in the respective $n$-perfluoroalkanes. The substitution of an $\alpha-(\omega$-)fluorine creates a dipole that increases with the difference in electronegativity between the substitute atom and fluorine. The enhanced polar interactions between the fluoroalkane and water lead to a higher water solubility in the $\alpha-(\omega$-)substituted $n$-fluoroalkanes.

Acknowledgment. The authors thank financial support from Fundação para a Ciência e a Tecnologia (POCTI/EQU/44427/ 2002) and Ph.D. grant (SFRH/BD/14134/2003) of Mara G. Freire. They also acknowledge Bernd Schröder and Ana Dias for useful discussions, and the suggestions of the anonymous reviewer that helped to improve the final version of this manuscript.

\section{References and Notes}

(1) Nishikido, J.; Nakajima, H.; Saeki, T.; Ishii, A.; Mikami, K. Synlett 1998, $12,1347$.

(2) Horvath, I. T.; Rabai, J. Science 1994, 266, 72.

(3) Johnston, K. P.; Harrison, K. L.; Clarke, M. J.; Howdle, S. M.; Heitz, M. P.; Bright, F. V.; Carlier, C.; Randolph, T. W. Science 1996, $271,624$.

(4) McClain, J. B.; Betts, D. E.; Canelas, D. A.; Samulski, E. T.; DeSimone, J. M.; Londono, J. D.; Cochran, H. D.; Wignall, G. D.; ChilluraMartino, D.; Triolo, R. Science 1996, 274, 2049.

(5) Swinton, S. L. Chemical Thermodynamics; The Chemical Society, 1978; Vol. 2.

(6) Compliance Assessment of the Portsmouth Gaseous Diffusion Plant; DOE/EH-0144; U.S. Department of Energy, U.S. Government Printing Office: Washington, DC, 1990; pp 3-20.

(7) Riess, J. G. Chem. Rev. 2001, 101, 2797.

(8) Dias, A. M. A.; Freire, M. G.; Coutinho, J. A. P.; Marrucho, I. M. Fluid Phase Equilib. 2004, 222-223, 325.

(9) Freire, M. G.; Dias, A. M. A.; Coelho, M. A. Z.; Coutinho, J. A. P.; Marrucho, I. M. J. Colloid Interface Sci. 2005, 286, 224.

(10) Melo, M. J. P.; Dias, A. M. A.; Blesic, M.; Rebelo, L. P. N.; Vega, L. F.; Coutinho, J. A. P.; Marrucho, I. M. Fluid Phase Equilib. 2006, 242, 210 .

(11) Song, W.; Rossky, P. J.; Maroncelli, M. J. Chem. Chem. Phys. 2003, 119, 9145.

(12) Lo Nostro, P.; Scalise, L.; Baglioni, P. J. Chem. Eng. Data 2005, 50,1148 .
(13) Morgado, P.; McCabe, C.; Filipe, E. J. M. Fluid Phase Equilib. 2005, 228, 389.

(14) Dulce, C.; Tinè, M. R.; Lepori, L.; Matteoli, E. Fluid Phase Equilib. 2002, 199, 197.

(15) Shields, R. R. J. Electrochem. Soc. 1976, 254 C.

(16) Albrecht, E.; Baum, G.; Bellunato, T.; Bressan, A.; Torre, S. D.; D’Ambrosio, C.; Davenport, M.; Dragicevic, M.; Pinto, S. D.; Fauland, P.; Ilie, S.; Lenzen, G.; Pagano, P.; Piedigrossi, D.; Tessarotto, F.; Ullaland, O. Nucl. Instrum. Methods Phys. Res., Sect. A 2003, 510, 262.

(17) Rotariu, G. J.; Fraga, D. W.; Hildebrand, J. H. J. Am. Chem. Soc. 1952, 74, 5783 .

(18) Deschamps, J.; Gomes, M. F. C.; Pádua, A. A. H. J. Fluorine Chem. 2004, 125, 409 .

(19) Freire, M. G.; Razzouk, A.; Mokbel, I.; Jose, J.; Marrucho, I. M.; Coutinho, J. A. P. J. Chem. Eng. Data 2005, 50, 237.

(20) Kabalnov, A. S.; Makarov, K. N.; Shcherbakova, D. V. J. Fluorine Chem. 1990, 50, 271.

(21) Dias, A. M. A.; Bonifácio, R. P.; Marrucho, I. M.; Pádua, A. A. H.; Gomes, M. F. C. Phys. Chem. Chem. Phys. 2003, 5, 543.

(22) Dias, A. M. A.; Pàmies, J. C.; Coutinho, J. A. P.; Marrucho, I. M.; Vega, L. F. J. Phys. Chem. B 2004, 108, 1450.

(23) Gomes, M. F. C.; Deschamps, J.; Mertz, D. H. J. Fluorine Chem. 2004, 125, 1325 .

(24) Dias, A. M. A.; Caço, A. I.; Coutinho, J. A. P.; Santos, L. M. N. B. F.; Piñeiro, M. M.; Vega, L. F.; Gomes, M. F. C.; Marrucho, I. M. Fluid Phase Equilib. 2004, 225, 39.

(25) Freire, M. G.; Dias, A. M. A.; Coutinho, J. A. P.; Coelho, M. A. Z.; Marrucho, I. M. Fluid Phase Equilib. 2005, 231, 109.

(26) Yaminsky, V. V.; Vogler, E. A. Curr. Opin. Colloid Interface Sci. 2001, 6, 342 .

(27) Widom, B.; Bhimalapuram, P.; Koga, K. Phys. Chem. Chem. Phys. 2003, 5, 3085 .

(28) Chandler, D. Nature (London) 2005, 437, 640.

(29) Tsonopoulos, C. Fluid Phase Equilib. 1999, 156, 21.

(30) Adkins, C. J. Equilibrium Thermodynamics; McGraw-Hill: London, 1968.

(31) Nilsson, S.-O. J. Chem. Thermodyn. 1986, 18, 877.

(32) Ben-Naim, A. Solvation Thermodynamics; Plenum Press: New York, 1987

(33) Ben-Naim, A. J. Solution Chem. 2001, 30, 475.

(34) Ben-Naim, A. J. Chem. Phys. 1984, 81, 2016.

(35) Dias, A. M. A. Gas Solubilities in Blood Substitutes. Ph.D. Thesis in Chemical Engineering, University of Aveiro, Portugal, 2005.

(36) Dias, A. M. A.; Gonçalves, C. M. B.; Caco, A. I.; Santos, L. M. N. B. F.; Piñeiro, M. M.; Vega, L. F.; Coutinho, J. A. P.; Marrucho, I. M. J. Chem. Eng. Data 2005, 50, 1328.

(37) Dias, A. M. A.; Caço, A. I.; Coutinho, J. A. P.; Santos, L. M. N. B. F.; Piñeiro, M. M.; Vega, L. F.; Gomes, M. F. C.; Marrucho, I. M. Fluid Phase Equilib. 2004, 225, 39.

(38) Dias, A. M. A.; Gonçalves, C. M. B.; Legido, J. L.; Coutinho, J. A. P.; Marrucho, I. M. Fluid Phase Equilib. 2005, $238,7$.

(39) NIST Chemistry WebBook at http://webbook.nist.gov/.

(40) ABCR, Specialists in Silicone and Fluorine Chemistry at http:// www.abcr.de/.

(41) ChemExper - Catalog of Chemical Suppliers at http://www.chemexper.com/.

(42) Miller, J. C.; Miller, J. N. Statistical for Analytical Chemistry, 3rd ed.; PTR Prentice Hall: Chichester, 1993.

(43) Marsh, K. N. Recommended Reference Materials for the Realization of Physicochemical Properties; Blackwell: Oxford, 1987.

(44) Freire, M. G.; Carvalho, P. J.; Queimada, A. J.; Marrucho, I. M.; Coutinho, J. A. P. J. Chem. Eng. Data 2006, 51, 1820.

(45) McLure, I. A.; Sipowska, J. T.; Pegg, I. L. J. Chem. Thermodyn.1982, 14, 733 .

(46) Graziano, G. J. Phys. Chem. B 2005, 109, 981.

(47) Frisch, M. J.; Trucks, G. W.; Schlegel, H. B.; Scuseria, G. E.; Robb, M. A.; Cheeseman, J. R.; Montgomery, J. A., Jr.; Vreven, T.; Kudin, K N.; Burant, J. C.; Millam, J. M.; Iyengar, S. S.; Tomasi, J.; Barone, V.; Mennucci, B.; Cossi, M.; Scalmani, G.; Rega, N.; Petersson, G. A.; Nakatsuji, H.; Hada, M.; Ehara, M.; Toyota, K.; Fukuda, R.; Hasegawa, J.; Ishida, M.; Nakajima, T.; Honda, Y.; Kitao, O.; Nakai, H.; Klene, M.; Li, X.; Knox, J. E.; Hratchian, H. P.; Cross, J. B.; Adamo, C.; Jaramillo, J.; Gomperts, R.; Stratmann, R. E.; Yazyev, O.; Austin, A. J.; Cammi, R.; Pomelli, C.; Ochterski, J. W.; Ayala, P. Y.; Morokuma, K.; Voth, G. A.; Salvador, P.; Dannenberg, J. J.; Zakrzewski, V. G.; Dapprich, S.; Daniels, A. D.; Strain, M. C.; Farkas, O.; Malick, D. K.; Rabuck, A. D.; Raghavachari, K.; Foresman, J. B.; Ortiz, J. V.; Cui, Q.; Baboul, A. G.; Clifford, S.; Cioslowski, J.; Stefanov, B. B.; Liu, G.; Liashenko, A.; Piskorz, P.; Komaromi, I.; Martin, R. L.; Fox, D. J.; Keith, T.; Al-Laham, M. A.; Peng, C. Y.; Nanayakkara, A.; Challacombe, M.; Gill, P: M. W.; Johnson, B.; Chen, W.; Wong, M. W.; Gonzalez, C.; Pople, J. A. Gaussian 03, revision B.03; Gaussian, Inc.: Pittsburgh, PA, 2003. 